\title{
POINT CLOUD REGISTRATION AND VIRTUAL REALIZATION OF LARGE SCALE AND MORE COMPLEX HISTORICAL STRUCTURES
}

\author{
C. Altuntas*, F. Yildiz \\ Selcuk University, Engineering Faculty, Department of Geomatics, 42075, Selcuklu, Konya, Turkey - \\ caltuntas@selcuk.edu.tr \\ Commission V
}

KEY WORDS: Terrestrial, Laser Scanning, Point Cloud, Registration, Accuracy, Three-Dimensional, Cultural Heritage

\begin{abstract}
:
Digital information technology always needs more information about object and its relations. Thus, three-dimensional (3D) models of historical structures are created for visualize and documentation of them. Laser scanner performs collecting spatial data with fast and high density. 3D modeling is extensively performed by terrestrial laser scanner (TLS) with high accuracy. At the same time, point cloud registration of large scale objects must be performed precisely for high accuracy 3D modeling. In this study, 3D model was created by measuring the historical Mevlana Museum in Konya with terrestrial laser scanner. Outside and inside point clouds were registered relation one of the point clouds selected from the measurements. In addition accuracy evaluation was performed for created point cloud model. In addition, important details were specifically imaged by mapping photographs onto the point cloud and detail measurements were given.
\end{abstract}

\section{INTRODUCTION}

The historical structures have to be documented with all the details in order to maintain and restore to their original forms and re-build when they are destroyed. Three-dimensional (3D) digital models of historical buildings can be created by measuring all the details with optical laser scanning techniques very quickly, precisely, and archived in digital environments. 3D measurement and object modeling are used in many fields such as computer and robotic technology, object modelling, virtual reality, information system, documentation of historical structures, medical applications etc. All kinds of geometric information about the object (volume, length, location, digital elevation model, cross-section) can be obtained from 3D digital models. 3D digital models of the historical structures enable to be restored in accordance with their originals in actual sizes in case of deformation and destruction.

In this study, 3D digital model of Mevlana Museum (Mevlana Mausoleum) was created with TLS. Also, the accuracy of 3D point cloud model generated was examined. In addition, virtual models and orthophoto images were created for important details by mapping photographs onto the point cloud.

\section{THE STUDY OBJECT: MEVLANA MUSEUM}

Mevlana Museum, containing the mausoleum of Mevlana Jalaluddin Rumi, is a complex of buildings with a Masjid (small mosque), Semahane, Matbah, dervish cells, fountain, seb-i aruz pool and a chalabi room around. Of the structures which made up the complex the mausoleum was built during the Seljuq period. The other outlying buildings belongs to the Karamanids and Ottoman period. Mevlana Museum is located in the city center of Konya, Turkey (Figure 1).

The Mevlana Museum was built on rosarium of Seljuk Palace. Its land had been gifted by Sultan Alaaddin Keykubat to
Sultanul-Ulema Bahaeddin Veled who is the father of Mevlana. Sultanul-Ulema was buried in the present mausoleum after his death. The mausoleum where the Green Dome (Kubbe-i Hadra) is located was built with the permission of the son of Mevlana, Sultan Veled, by Mimar Tebrizli Bedrettin in 1274 after the death of Mevlana. From that time, the construction activities continued up to the end of 19th century (url-1).

The Mevlevi Dervish Lodge and the mausoleum began to serve as a museum under the name "Konya Asar-1 Atika Museum" in 1926. In 1954 the exhibition and arrangement of the museum was revised and the name of the museum was changed as Mevlana Museum (url-1).

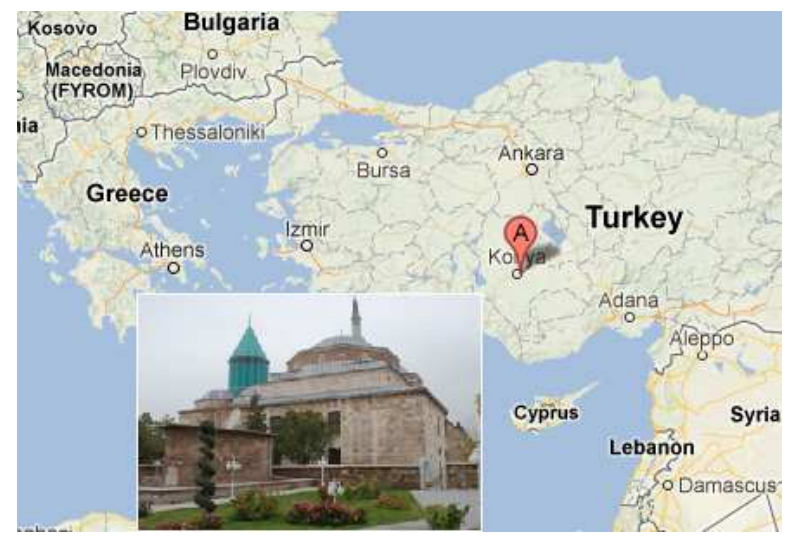

Figure 1. Location of Mevlana Museum (Map is from Google Earth).

The courtyard of the museum is entered from "Dervisan Gate". In the east of the courtyard there is the main building having Semahane, Masjid parts and the graves of Mevlana and his family members (url-1). 


\section{MEASUREMENT: TERRESTRIAL LASER SCANNING}

Terrestrial laser scanning is a very fast measurement method compared to the traditional techniques. The 3D point locations of measuring space can be measured in the form of point series with high accuracy (Lichti and Gordon, 2004). Basic measurement data, orthophoto images, solid surface models and texture mapped 3D models can be created from the laser scanner point cloud.

TLSs use direct time-of-flight, indirect time-of-flight (phaseshift) and triangulation methods to measure of distance. The measurement distance of scanners using triangulation method is up to $10 \mathrm{~m}$. Although the measurement distance of scanners measuring direct time-of-flight is around a few kilometers, the measurement distance of scanners measuring indirect time-offlight is around $300 \mathrm{~m}$. On the other hand the measurement accuracy of the devices that measure indirect time-of-flight is higher. In general the measurement accuracy of laser scanners varies from a few millimeters to $1 \mathrm{~cm}$ in the distance of $100 \mathrm{~m}$ (Pfeifer and Briese, 2007). The laser scanners are devices that can be installed on tripod and perform panoramic scanning at 360 degrees horizontally and at 270 degrees vertically. In this study, laser scanning measurements were achieved with Optech Ilris 3D laser scanner device (Figure 2). This device can measure 2500 points in a second with direct time-of-flight method and the point location accuracy is $7 \mathrm{~mm}$ in $100 \mathrm{~m}$ (Optech, 2013).

The most important process in 3D modeling with terrestrial laser scanner is the registration of the scans performed for the same object from different stations in a common coordinate system. Iterative Closest Point (ICP) algorithm (Chen and Medioni, 1992; Besl and McKay, 1992) is the most widely used method in the application and its accuracy is very high. In this method, after finding the nearest points between the reference and target (moving) point cloud that will be registered, translation and rotation parameters are calculated with those points. Many techniques have been developed so far in different names for shortening the calculation time of ICP method and using different data sets together (Sharp et al., 2002; Chetverikov et al., 2002; Fitzgibbon, 2003; Wyngaerd and Van Gool, 2003; Makadia et al., 2006; Liu, 2006; Bae and Lichti, 2008).

In this study, laser scanning was performed with Optech Ilris 3D laser scanner (Fig. 2). The outside surface of the museum was measured with scan point interval of about $1.5 \mathrm{~cm}$. The doors having small details and embellishments were measured with scan point interval of $1 \mathrm{~cm}$ and $3 \mathrm{~mm}$ respectively (Figure 3). And in the roof, the distance between the scan points is $3 \mathrm{~cm}$ long. Each scanning was performed to be overlapped with other scans. The laser scanning measurements of the outside surfaces of the museum was carried out from distance of about 25 meters. The upper parts of the museum were measured from the minarets of Selimiye Mosque located next to the museum and the measuring distance is approximately $60 \mathrm{~m}$ long. The sections of the roof that cannot be measured from here were measured by climbing onto the roof. The indoor areas were measured with scan point interval of $1 \mathrm{~cm}$. The detail based areas were measured with scan point interval of $3 \mathrm{~mm}$. The laser scanning of outside and inside details were performed from 110 and 72 stations respectively.

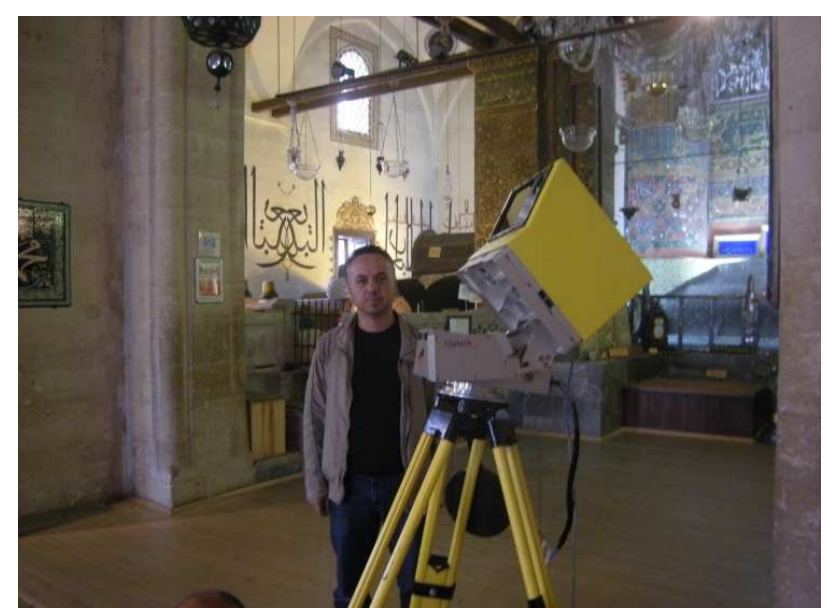

Figure 2. Laser scanning in Huzur-1 Pir section of Mevlana Museum.

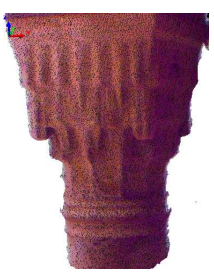

Figure 3. Point cloud of the column embellishment on the door of Masjid.

\section{THE RESULTS}

\subsection{Point Cloud Registration}

The registration of point cloud is combination of overlapping point cloud as one of them is fixed and the other is translating and rotating. According to this, registration of second point cloud to the first is given $\mathrm{Eq}(1)$

$$
\left[\begin{array}{l}
x \\
Y \\
z
\end{array}\right]=\mathbb{R}\left[\begin{array}{l}
x \\
y \\
Z
\end{array}\right]+\left[\begin{array}{l}
t_{x} \\
t_{y} \\
t_{z}
\end{array}\right]
$$

Where; $[X Y Z]^{\mathrm{T}}$ and $[x y z]^{\mathrm{T}}$ are reference and target point cloud coordinates respectively. $\mathrm{R}$ is rotation matrice and $\left[\begin{array}{ll}t_{x} & t_{y} \\ t_{z}\end{array}\right]^{\mathrm{T}}$ are translations between coordinate axis. The registration of the point clouds was executed in PolyWorks IMAlign modul (InnovMetric, 2007) with ICP method in this study. In application of the method, first point cloud is imported to the program and selected as reference point cloud by locking. Then all other measurements will be registered in the coordinate system of this point cloud. The second point cloud overlapped with this is imported to the program and the coordinates of this point cloud are registered to the reference point cloud. The first two point clouds registered are grouped before importing of the third point cloud on to the program. This process continues up to finish registering all point clouds in this way.

In order to apply ICP method, initially, approximate registration parameters were calculated with at least three common points chosen from both. Then, the exact registration of the point clouds was applied with ICP method. After registering all measurements in this way, global registration was made to minimize the cumulative errors originated from consecutive 
registrations. Thus, the measurement group was canceled, the locks were removed and registration parameters of all measurements were calculated simultaneously (global registration) and only the first point cloud (or any one chosen) was locked. In this calculation, standard deviations of the registrations are around $0.9 \mathrm{~cm}$, and the maximum standard deviation is $2.19 \mathrm{~cm}$ (Table 1). The indoor and outdoor point cloud models were created in relation to two coordinate systems by selecting different point clouds as references (Figure 4, Figure 5, Figure 6).

Table 1. Global registration results with ICP.

\begin{tabular}{|c|c|c|c|c|c|}
\hline \multirow{2}{*}{$\begin{array}{l}\text { Point } \\
\text { Cloud } \\
\text { Model }\end{array}$} & \multirow{2}{*}{$\begin{array}{l}\text { Point } \\
\text { Cloud } \\
\#\end{array}$} & \multirow{2}{*}{$\begin{array}{c}\text { Iterati } \\
\text { on } \\
\#\end{array}$} & \multicolumn{3}{|c|}{ Standard Deviation $(\mathrm{cm})$} \\
\hline & & & Min & Median & Max \\
\hline Outside & 110 & 50 & 0.44 & 0.92 & 2.19 \\
\hline Inside & 72 & 32 & 0.53 & 0.80 & 1.33 \\
\hline
\end{tabular}
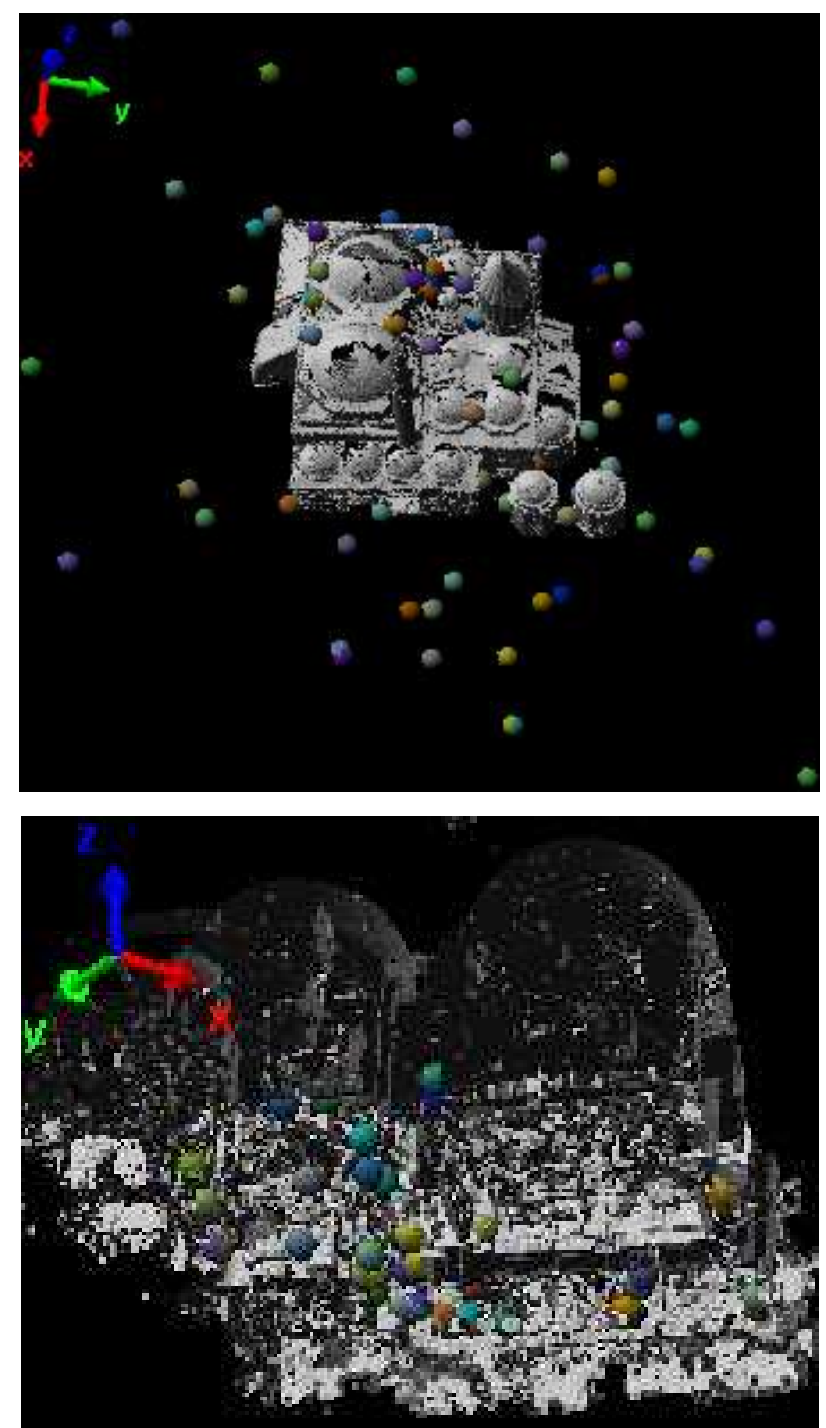

Figure 4. The laser scanning stations of outside (above) and inside (below) measurement of the Mevlana Museum.

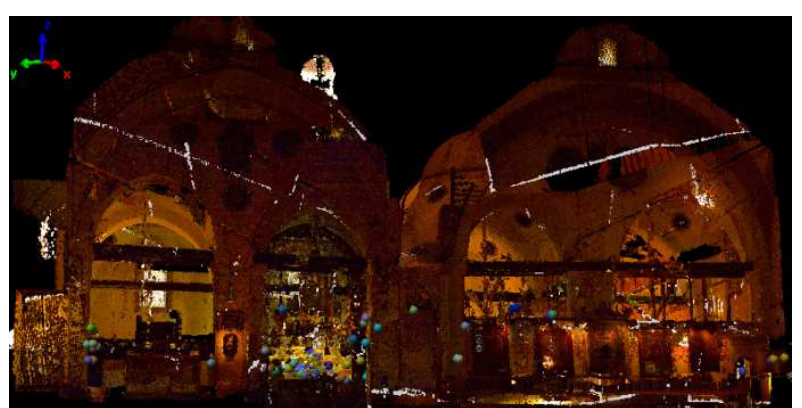

Figure 5. Intersectional (East-West directions) visualization of Semahane (left) and Masjid (right) sections (South side).

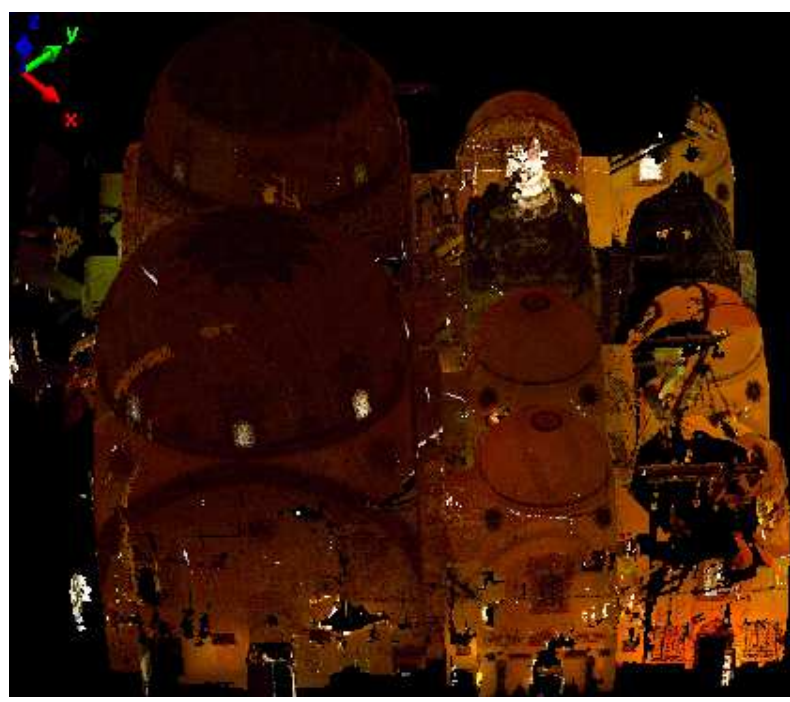

Figure 6. The inside 3D point cloud model with color.

\subsection{Accuracy Evaluation of 3D Point Cloud Model}

The global registration results show an accuracy criteria to created 3D model. The point clouds were registered with small standard deviation in global registration. Nevertheless. we computed the other accuracy criteria by Eq (2) given Aquilera et al. (2009).

$$
d f=\sqrt{\sum_{i=1}^{N} \sum_{j=2}^{N}\left[\left(d_{i}^{j}\right)_{I T R F}-\left(d_{i}^{j}\right)_{T L S}\right]^{2} / n} \quad \mathrm{i}<\mathrm{j}
$$

In this equation, the $(d)_{\text {ITRF }}$ is distances computed with ITRF2005 coordinates and $(d)_{T L S}$ is distances computed with point cloud coordinates between $\mathrm{i}$ and $\mathrm{j}$ control points. Being close to zero of $d f$ means the similarity of the coordinates in both two systems and it is an accuracy criteria for the model created with laser scanner measurements (Aquilera et al., 2009). The distances between 16 and 20 control points were used to compute accuracy criteria for outdoor and indoor surface models respectively (Figure 7). The $d f$ accuracy criteria were given in Table 2. According to these results, in considering of the accuracy $(7 \mathrm{~cm} @ 100 \mathrm{~m})$ taken from laser scanner, the accuracy of the obtained 3D point cloud model is quite good (Table 2). 


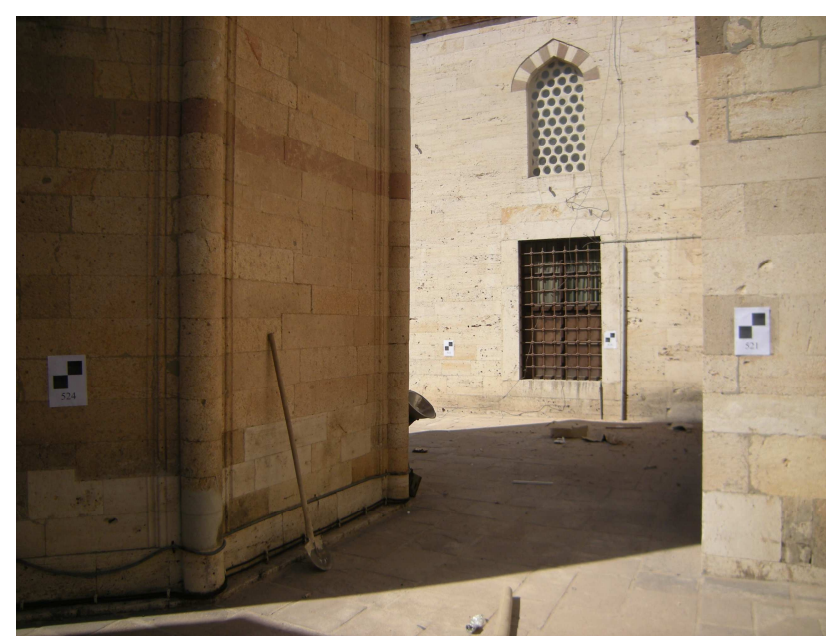

Figure 7. Control points

Table 2. The accuracy evaluation results for the outside and inside $3 \mathrm{D}$ point cloud model.

\begin{tabular}{|c|c|c|c|}
\hline $\begin{array}{c}\text { Point cloud } \\
\text { model }\end{array}$ & $\begin{array}{c}\text { Control } \\
\text { points\# }\end{array}$ & Sides\# & $\mathrm{df}(\mathrm{m})$ \\
\hline Outside & 16 & 15 & 0.0234 \\
\hline Inside & 20 & 19 & 0.0242 \\
\hline
\end{tabular}

\subsection{Virtual Realization}

The point cloud model was texture mapped in order to image the important details better. The details that would be texture mapped are photographed from the front as possible as. The imagery was captured using a Nikon D80 camera that had been calibrated before use.

In order to map photograph texture the triangulated (mesh) model surface is created from the point cloud. 3D model image which the photograph texture mapped is created by matching the triangle surfaces created with photograph surfaces. The coordinates of the photograph's projection center are calculated with at least three control points (more control points must be used in order to get better results) whose photograph and point cloud coordinates are known (Kraus, 2007).

In this study, the triangulated surface was created in PolyWorks program. After creating the triangulated model, editing process can be done in IMEdit modul. The triangulated image of the dome on the Silver Sill are given in Figure 8.

PI-3000 software (ver.3.21) was used to map photograph texture on the triangulated model of the object. The triangulated model from PolyWorks was transferred to PI-3000 program by saving as dxf format and the photographs taken with NikonD80 camera were imported to the program. After registering the photographs to the object (point cloud) coordinate system 3D virtual model and orthophoto image were created by mapping photograph texture on the triangulated model (Figure 8).
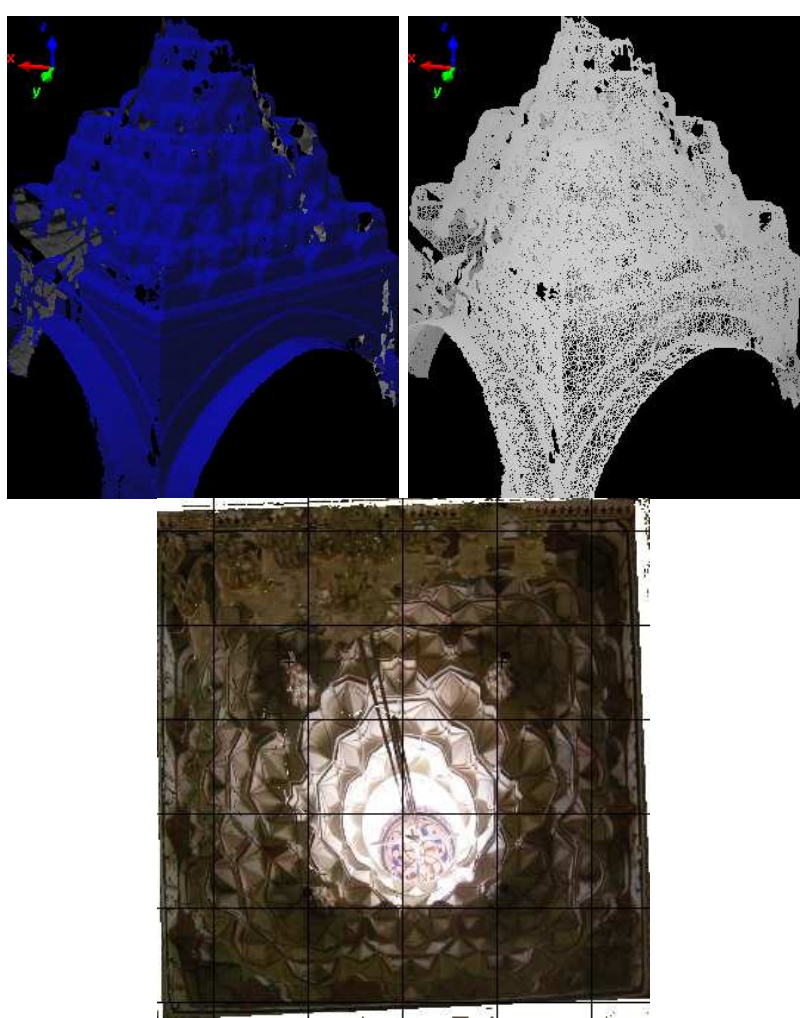

Figure 8. Point cloud, mesh and texture mapped 3D visualization of dome of Silver Sill.

\subsection{Dimensions and Digital Elevation Model}

Ground plan of the Museum was created from the point cloud model by using PolyWorks software. The horizontal plane was defined as parallel to XY axis and cross-section was created by intersecting the point cloud model. This cross-section is ground plane of the museum and dimensions were extracted from it (Figure 10). In addition, dimensions of the significant details were measured from 3D point cloud model (Figure 9,11,12,13). Furthermore, digital elevation model was created from point cloud model (Figure 14, 15). Digital elevation model shows heights ( $\mathrm{Z}$ axis) of the details as $\mathrm{XY}$ axis are horizontal plane.

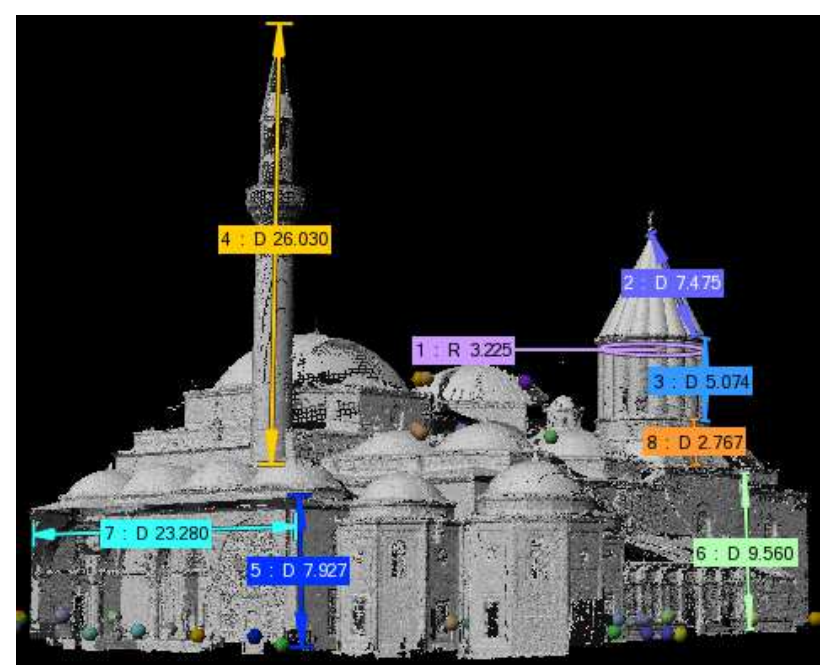

Figure 9. Dimensions of outside details (units are meters). 

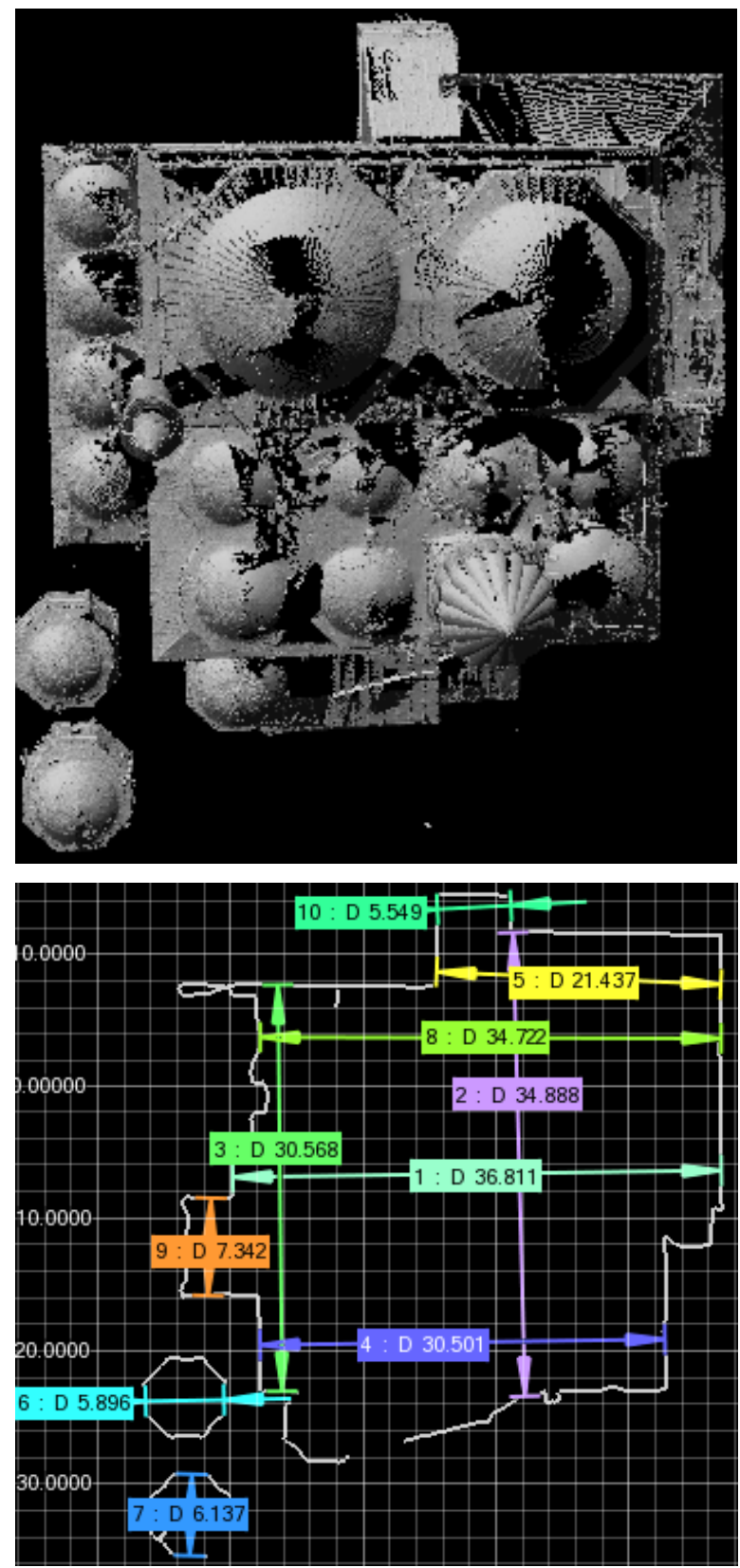

Figure 10. Point cloud (above) and ground plan (below) of the Mevlana Museum (units are meters).

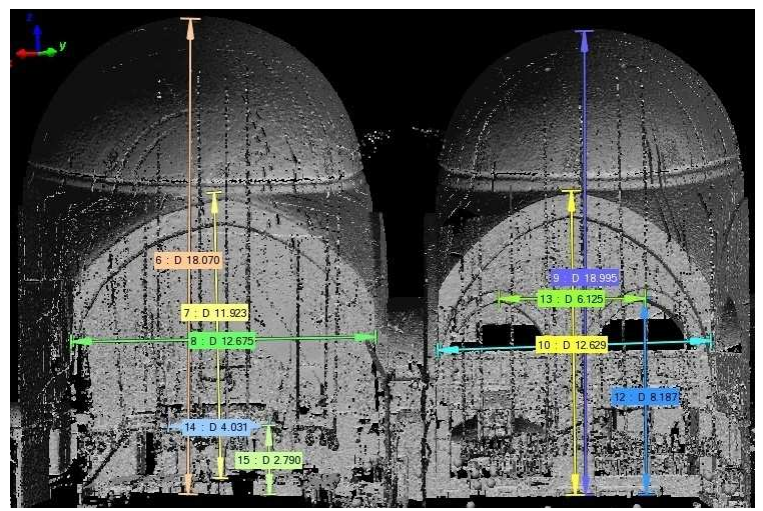

Figure 11. Dimensions in Masjid (left) and Semahane (right) parts (North side) (units are meters).

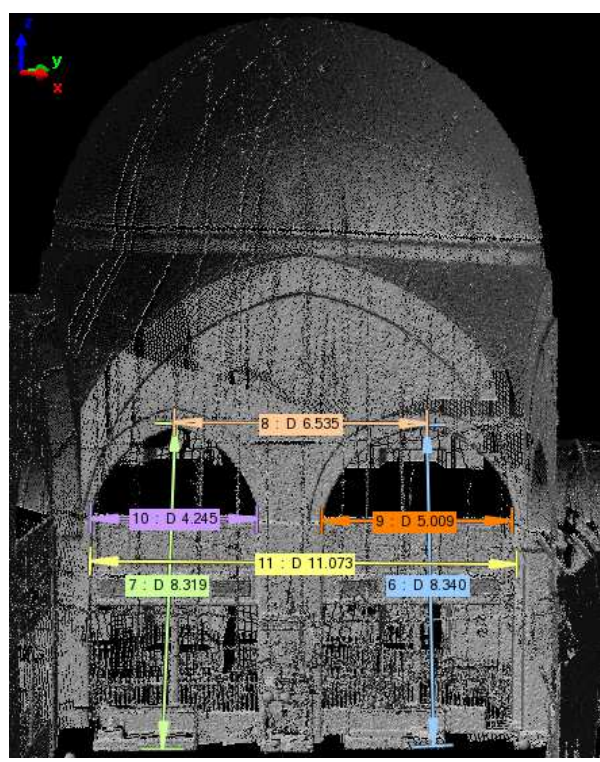

Figure 12. Dimensions from Semahane section (East side) (units are meters).
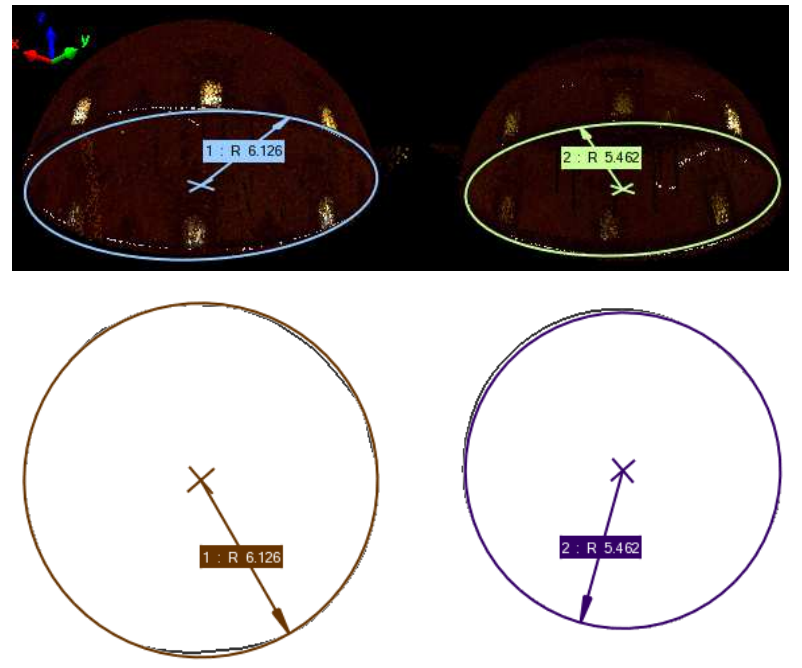

Figure 13. Dimensions of Masjid (left) and Semahane (right) domes (units are meters)
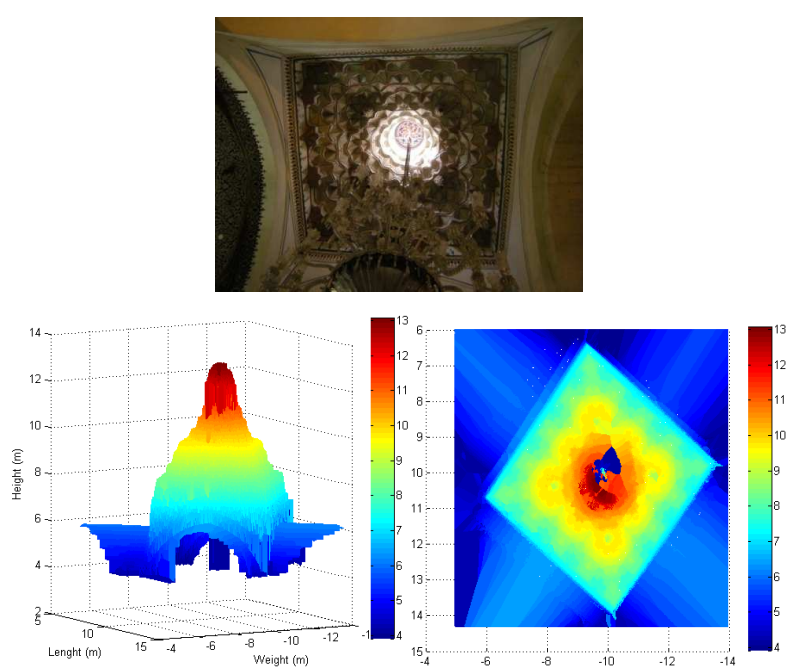

Figure 14. Digital elevation model of dome of Silver Sill (units are meters). 


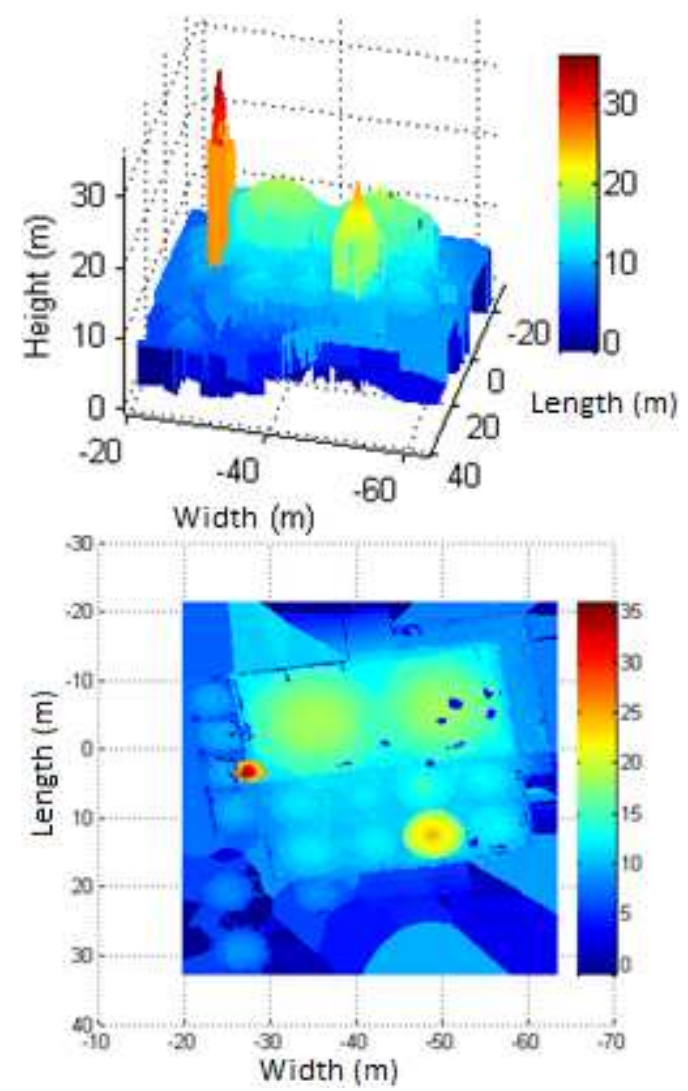

Figure 15. Digital elevation model of Mevlana Museum (units are meters).

\section{CONCLUSIONS AND FUTURE STUDY}

In this study, 3D model of Mevlana Museum was created by using TLS. The global registration results and distance comparison show that the $3 \mathrm{D}$ model was created with high accuracy despite a large number of measurements and complex structure of the building. And also the present images of the important details were documented by photograph texture mapping. Furthermore digital elevation model created from point cloud model gives comparative information about heights of the details. As a consequence, the documentation of Mevlana Museum which is of historical importance and visited by many people has been made. The further study will be focused on the measurement unimaged details by laser scanner with the other measurement techniques and data integration and fusion. In addition the created point cloud model will be georeferenced for connecting with the other graphical data and querying all information of the object exactly.

\section{Acknowledgements}

This study was supported with funding by The Scientific and Technological Research Council of Turkey (TUBITAK) with project number $112 \mathrm{Y} 025$.

\section{References}

Aquilera, DG, Gonzalvez, PR, Lahoz, JG., 2009. An automatic procedure for co-registration of terrestrial laser scanners and digital cameras. ISPRS Journal of Photogrammetry and Remote Sensing, 64(2009), pp. 308-316.
Bae, K, Lichti, DD., 2008. A Method for automated registration of unorganised point clouds. ISPRS Journal of Photogrammetry and Remote Sensing, 63(2008), pp. 36-54.

Besl, PJ., McKay, ND., 1992. A method for registration of 3-D shapes. IEEE Transactions on Pattern Analysis and Machine Intelligence, 14(2), pp. 239-256.

Chen, Y., Medioni, G., 1992. Object modelling by registration of multiple range images. Image and Vision Computing, 10(3), pp. 145-155.

Chetverikov, D., Svirko, D., Stepanov, D., Krsek, P., 2002. The trimmed iterative closest point algorithm. Proceedings of IEEE Conference on Pattern Recognition, Quebec City, 11-15 August, pp. 545-548.

Fitzgibbon, AW., 2003. Robust registration of 2D and 3D point sets. Image and Vision Computing, 21(2003), pp. 1145-1153.

InnovMetric. Polyworks Software (ver 9) Beginner's Guide 2007.

Kraus K., 2007. Photogrammetry: Geometry From Images and Laser Scans, Walter de Gruyter, Berlin, New York.

Lichti, DD., Gordon, SJ., 2004. Error propagation in directly georeferenced terrestrial laser scanner point clouds for cultural heritage recording. Proceedings of FIG Working Week, Athens, Greece, 22-27 May, on CD.

Liu, Y., 2006. Automatic registration of overlapping 3D point clouds using closest points. Image and Vision Computing, 24(2006), pp. 762-781.

Makadia, A., Patterson, A., Daniilidis, K., 2006. Fully automatic registration of $3 \mathrm{D}$ point clouds. Proceedings of IEEE Conference on Computer Vision and Pattern Recognition, New York, 18-20 June, pp. 1297-1304.

Optech, 2013. Technical overview Ilris-3D specifications, http://www.optech.ca/ i3dtechoverview-ilris.htm (access: 10 Jan 2013).

Pfeifer, N., Briese, C., 2007. Geometrical aspects of airborne laser scanning and terrestrial laser scanning. The International Archives of the Photogrammetry, Remote Sensing and Spatial Information Sciences, Espoo, Finland, 36(3-W5/2), pp. 311319.

Sharp, GC., Lee, SW., Wehe, DK., 2002. ICP registration using invariant features. IEEE Transactions on Pattern Analysis and Machine Intelligence, 24(1), pp. 90-102.

url-1, T.C. Republic of Turkey Ministry of Culture and Tourism. http://www.kulturvarliklari.gov.tr/TR,43870/konya--mevlana-muzesi.html (access: 3 Dec 2012).

Wyngaerd, JV., Van Gool, L., 2003. Combining texture and shape for automatic crude patch registration. Proceeding of IEEE Conference on 3-D Digital Imaging and Modeling, Alberta, Canada, 6-10 Oct., pp. 179-186. 